\title{
Desenvolvimento de plantas, produção e qualidade de bulbos de alho sob condições de deficiência de água no solo
}

\author{
Waldir A. Marouelli; Washington L. C. Silva; Celso L. Moretti \\ Embrapa Hortaliças, C. Postal 218, 70.359-970 Brasília, DF. E-mail: waldir@cnph.embrapa.br
}

\begin{abstract}
RESUMO
Avaliou-se o comportamento de plantas de alho submetidas a diferentes níveis de água no solo, em dois estádio de desenvolvimento. O experimento foi conduzido na Embrapa Hortaliças, Brasília, DF. Os tratamentos, dispostos em esquema fatorial 4 x 4 , resultaram da combinação de quatro tensões de água no solo no estádio vegetativo $(20 ; 40 ; 80$ e $160 \mathrm{kPa})$ e quatro no de bulbificação $(20$; $40 ; 80$ e $160 \mathrm{kPa}$ ). Plantas submetidas à deficiência hídrica, em qualquer dos estádios, tiveram o desenvolvimento, a produtividade comercial, o tamanho médio de bulbos e a eficiência do uso de água reduzidos em até $70 \%, 63 \%, 31 \%$ e $57 \%$, respectivamente. O crescimento de plantas e a produtividade de bulbos foram negativamente afetados mesmo para condições de deficiência moderada de água no solo $(40 \mathrm{kPa})$. O número de bulbos por unidade de área foi reduzido linearmente apenas quando as plantas foram submetidas à deficiência hídrica no estádio vegetativo. As percentagens de bulbos pseudoperfilhados, de chochos e de perda de massa de bulbos não foram afetadas significativamente por tensões entre $20 \mathrm{e}$ $160 \mathrm{kPa}$.
\end{abstract}

Palavras-Chave: Allium sativum, irrigação, manejo de água, nível de água no solo, relação solo-água-planta.

\begin{abstract}
Plant growth, yield and quality of garlic bulbs under soil water deficit conditions

The experiment was carried out at Embrapa Hortaliças, Brasília, Brazil, aiming to evaluate the response of garlic plants to different water regimes in the soil at two development stages. Treatments, arranged in a factorial scheme $4 \times 4$, resulted from the combination of four water tensions in the vegetative stage $(20 ; 40 ; 80$; and 160 $\mathrm{kPa})$ and four in the bulbfication $(20 ; 40 ; 80$; and $160 \mathrm{kPa})$. Plants submitted to soil water deficits in any crop stage had the vegetative growth, marketable yield, bulb size, and water use efficiency reduced up to $70 \%, 63 \%, 31 \%$, and $57 \%$, respectively. Plant vegetative growth and bulb yield were negatively affected even for moderate water deficit in the soil ( $40 \mathrm{kPa}$ ). The number of bulbs per unit of area was linearly reduced only when the plants were submitted to water deficits in the vegetative stage. Percentage of dry and secondary bulb growth, and bulb weight losses were not statistically affected by tensions between 20 and $160 \mathrm{kPa}$.
\end{abstract}

Keywords: Allium sativum, irrigation, irrigation scheduling, soil water level, soil-water-plant relation.

\section{(Recebido para publicação em 17 de agosto de 2001 e aceito em 19 de março de 2002)}

$\mathrm{O}$ alho é uma hortaliça de grande importância econômica no Brasil, sendo seu cultivo realizado principalmente por pequenos agricultores. A área média anual cultivada, no período entre 1990 e 1999 , foi de 14,8 mil hectares, com produção de 72,3 mil toneladas. Desse total, cerca de $20 \%$ são cultivados na região de cerrados do Brasil Central, principalmente nos estados de Goiás e Minas Gerais (IBGE, 2000).

A água é o fator que mais freqüentemente afeta o desenvolvimento, a produção e a qualidade do alho. A deficiência de água no solo compromete principalmente o desenvolvimento das plantas e a produtividade de bulbos, enquanto que o excesso prejudica a qualidade e a conservação (Costa et al., 1993; Melo \& Oliveira, 1999; Marouelli et al., 2002). Como o alho é cultivado preferencialmente na estação fria, coincidindo com a época mais seca do ano, nas principais regiões produtoras, a ir- rigação é prática obrigatória para suprir as necessidades hídricas da cultura e garantir a obtenção de produtividade elevada e com bulbos de boa qualidade, especialmente nas áreas de produção de Minas Gerais, Goiás e Bahia. Também em Santa Catarina e Rio Grande do Sul, onde é freqüente a ocorrência de estiagens durante o período de cultivo, muitos agricultores já fazem o uso da irrigação para suplementar as necessidades hídricas das plantas (Pola \& Biasi, 1993). Muito embora seja uma prática comum entre muitos produtores, as irrigações são geralmente realizadas de forma empírica, apenas com base no senso prático do irrigante, sem ser consideradas as reais necessidades de água da cultura e a disponibilidade de água do solo cultivado.

Para garantir o sucesso da cultura, as irrigações devem ser realizadas antes que a disponibilidade de água no solo seja reduzida a níveis capazes de alterar o metabolismo das plantas e comprometer a produção (Marouelli et al., 1996). Vasconcellos et al. (1971) e Klar et al. (1972), avaliando tensões máximas de água no solo entre 30 e $1500 \mathrm{kPa}$, verificaram que a produtividade de bulbos de alho foi maximizada para a tensão de $50 \mathrm{kPa}$. Semelhantemente, Silva et al. (1981) recomendam que tensões máximas entre 40 e $50 \mathrm{kPa}$ favorecem o melhor desempenho da cultura. Estudos mais recentes (Pola \& Biasi, 1993; Marouelli et al., 2002), no entanto, indicam que a manutenção de tensões máximas entre 13 e $27 \mathrm{kPa}$ maximiza a produtividade. Além da divergência sobre a faixa de tensão ótima para o manejo da água de irrigação, não existem na literatura estudos sobre os efeitos de estresses hídricos nos diferentes estádios de desenvolvimento de plantas de alho. É sabido, todavia, que a grande maioria das hortaliças apresenta períodos mais ou menos sensíveis à deficiências de 
água no solo, sendo tais informações de vital importância para o adequado manejo de água ao longo de todo o ciclo de desenvolvimento das plantas (Marouelli et al., 1996).

Por outro lado, o chochamento e o pseudoperfilhamento, distúrbios genético-fisiológicos que depreciam a qualidade e reduzem a capacidade de conservação de bulbos de algumas cultivares, têm sido associados, dentre outros fatores, a níveis elevados de água no solo (Vasconcellos et al., 1971; Higazy et al., 1974; Costa et al., 1993).

Avaliou-se nesse estudo, para as condições edafoclimáticas da região de cerrados do Brasil Central, o efeito de deficiências crescentes de água no solo, aplicadas em dois estádios vegetativos da cultura do alho, no desenvolvimento de plantas, na produtividade e na qualidade de bulbos.

\section{MATERIAL E MÉTODOS}

O experimento foi conduzido no campo experimental da Embrapa Hortaliças, em Brasília, DF, em um Latossolo Vermelho distrófico, fase cerrado e de textura argilosa. A retenção de umidade do solo ( $\%$ vol.), na camada de 0-30 cm e intervalo de tensão entre 5 e $1500 \mathrm{kPa}$, foi ajustada à equação de van Genuchten (1980):

\section{Equação 1}

$$
\Theta(h)=25,4+14,8 /\left[1+(0,514 \times h)^{1,657}\right]^{0,397}
$$

O delineamento experimental foi de blocos ao acaso, com quatro repetições e 16 tratamentos dispostos em esquema fatorial $4 \times 4$. O primeiro fator correspondeu às tensões de água no solo no estádio vegetativo de 20; 40; 80 e 160 $\mathrm{kPa}$, e o segundo às tensões de água no solo no estádio de bulbificação de 20; $40 ; 80$ e $160 \mathrm{kPa}$, as quais corresponderam a cerca de $65 \%, 40 \%$, $25 \%$ e $15 \%$ de água disponível no solo, respectivamente.

A duração de cada estádio de desenvolvimento foi estabelecida da seguinte maneira: vegetativo - do estabelecimento inicial das plantas até o início da diferenciação do bulbo em bulbilhos $\left(21^{\circ}\right.$ ao $80^{\circ}$ dia após o plantio); de bulbificação - da diferenciação do bulbo até a paralisação das irrigações $\left(81^{\circ}\right.$ ao $140^{\circ}$ dia após o plantio).

A adubação de plantio foi realizada com $1.200 \mathrm{~kg} \mathrm{ha}^{-1}$ da fórmula 4-30-16, $150 \mathrm{~kg} \cdot \mathrm{ha}^{-1}$ de sulfato de magnésio, 15 $\mathrm{kg} \mathrm{ha}^{-1}$ de bórax e $15 \mathrm{~kg} \mathrm{ha}^{-1}$ de sulfato de zinco. Os bulbilhos da cultivar "Amarante" foram plantados em abril de 1992, no espaçamento de 0,20 m entre linhas de plantio e $0,10 \mathrm{~m}$ entre bulbilhos. A unidade experimental teve área útil de 4,8 $\mathrm{m}^{2}$, estando localizada dentro de uma área de plantio contínuo. Foram aplicados em cobertura $120 \mathrm{~kg}$ ha $^{-1}$ de uréia, parcelados em duas aplicações, aos 40 e 70 dias após o plantio (Menezes Sobrinho, 1997).

As irrigações foram realizadas por sistema de aspersão tipo convencional fixo e, para reduzir o tamanho das bordaduras e da área total do experimento, foram utilizados microaspersores com raio de alcance de 2,2 $\mathrm{m}$. Nos primeiros 20 dias após o plantio, todos os tratamentos foram irrigados uniformemente, sendo aplicada uma lâmina líquida de água de $4 \mathrm{~mm}$ a cada dois dias. A partir daí, o manejo da água de irrigação foi realizado com auxílio de tensiômetros, com manômetros de mercúrio, nos tratamentos com tensões de 20 e $40 \mathrm{kPa}$, e de blocos de resistência elétrica, calibrados individualmente, nos demais tratamentos. Os sensores foram instalados na profundidade efetiva média das raízes das plantas, a qual foi considerada de $0,15 \mathrm{~m}$ no estádio vegetativo e de $0,30 \mathrm{~m}$ no estádio de bulbificação. A lâmina líquida de água aplicada em cada irrigação foi computada a partir da equação 1 , sendo igual a necessária para que o solo retornasse à capacidade de campo na camada correspondente à profundidade efetiva das raízes (Marouelli et al., 1996). As irrigações foram paralisadas 15 dias antes do arranquio das plantas para garantir uma melhor conservação dos bulbos (Menezes Sobrinho, 1997).

Após o arranquio, realizado aos 155 dias do plantio, as plantas foram deixadas ao sol por dois dias e então levadas para um galpão ventilado para completar o processo de cura. O corte das ramas e a toalete dos bulbos foram realizados 60 dias após a colheita (Menezes Sobrinho, 1997).
Foram avaliadas as variáveis: número total de irrigações, lâmina líquida de água aplicada, massa seca da parte aérea, número de bulbos, produtividade total, comercial e de bulbos graúdos, massa média de bulbos, eficiência do uso de água, bulbos chochos aos 60 dias após a colheita e perda de massa de bulbos entre 60 e 120 dias e entre 120 e 180 dias após a colheita.

A classificação dos bulbos foi realizada conforme Portaria $n^{\circ}$ 242/92 do Ministério da Agricultura. À produtividade comercial incluiu-se os bulbos com diâmetro acima de $32 \mathrm{~mm}$, sem qualquer tipo de defeito, enquanto à produtividade de bulbos graúdos incluiu-se os bulbos comerciais das classes 6 e 7, ou seja, aqueles com diâmetro acima de 47 $\mathrm{mm}$. A massa média de bulbos foi determinada considerando os bulbos de todos os tamanhos, excluindo-se os chochos. A eficiência do uso de água foi computada pela relação entre a produtividade comercial de bulbos e a lâmina de água utilizada pela cultura, ou seja, a lâmina líquida de irrigação mais a precipitação efetiva. A precipitação efetiva foi computada conforme Marouelli et al. (1996).

Os dados obtidos foram submetidos à análise de variância, empregando-se o teste $\mathrm{F}$, sendo os efeitos significativos dos fatores considerados na análise de regressão para ajuste de modelos polinomiais ortogonais. Para que os níveis dos fatores independentes fossem igualmente espaçados, as tensões de água no solo foram expressas na unidade $\mathrm{pF}$, que é definida como o logaritmo na base $10 \mathrm{da}$ tensão expressa em centímetros de $\mathrm{H}_{2} \mathrm{O}$ (Reeve \& Carter, 1991). Assim, as tensões de 20; 40; 80 e $160 \mathrm{kPa}$ correspondem aos valores em $\mathrm{pF}$ de 2,31; 2,61; 2,91 e 3,21, respectivamente.

\section{RESULTADOS E DISCUSSÃO}

A lâmina líquida de água aplicada ao longo do ciclo de desenvolvimento das plantas (229 a $299 \mathrm{~mm}$ ) e o número total de irrigações realizadas (18 a 54) aumentaram com a redução da tensão de água no solo. A precipitação, no período de condução do experimento, foi de $94 \mathrm{~mm}$, com a precipitação efetiva variando entre $60 \mathrm{~mm}$, para o tratamen- 
Tabela 1. Funções de resposta da produção do alho para tensões de água no solo entre 2,31 a 3,21 pF, em dois estádios de desenvolvimento das plantas. Brasília/DF, Embrapa Hortaliças, 1992.

\begin{tabular}{llcc}
\hline \multicolumn{1}{c}{ Variável } & \multicolumn{1}{c}{ Equação de regressão } & $\mathbf{R}^{\mathbf{2}}$ & Ymáximo* $^{*}$ \\
\hline Massa seca parte aérea $\left(\mathrm{t} \mathrm{ha}^{-1}\right)$ & $\mathrm{Y}=8,744-0,559 \mathrm{~T}_{1}-4,042 \mathrm{~T}_{2}+0,627\left(\mathrm{~T}_{2}\right)^{2}$ & 0,79 & 1,462 \\
Produtividade total $\left(\mathrm{t} \mathrm{ha}^{-1}\right)$ & $\mathrm{Y}=18,400-2,779 \mathrm{~T}_{1}-1,717 \mathrm{~T}^{2}$ & 0,86 & 8,014 \\
Produtividade comercial $\left(\mathrm{t} \mathrm{ha}^{-1}\right)$ & $\mathrm{Y}=18,117-2,795 \mathrm{~T}_{1}-2,059 \mathrm{~T}_{2}$ & 0,85 & 6,904 \\
Produtividade bulbo graúdo $\left(\mathrm{t} \mathrm{ha}{ }^{-1}\right)$ & $\mathrm{Y}=4,713-0,835 \mathrm{~T}_{1}-0,662 \mathrm{~T}_{2}$ & 0,77 & 1,255 \\
Massa média de bulbos $(\mathrm{g})$ & $\mathrm{Y}=40,5-4,453 \mathrm{~T}_{1}-3,378 \mathrm{~T}_{2}$ & 0,73 & 22,4 \\
$\mathrm{~N}^{\circ}$ total de bulbos por $\mathrm{m}^{2}$ & $\mathrm{Y}=51,2-7,170 \mathrm{~T}_{1}$ & 0,62 & 34,6 \\
Eficiência uso de água $\left(\mathrm{g} \cdot \mathrm{L}^{-1}\right)$ & $\mathrm{Y}=4,88-0,834 \mathrm{~T}_{1}-0,418 \mathrm{~T}_{2}$ & 0,82 & 1,99 \\
\hline
\end{tabular}

$\mathrm{Y}, \mathrm{T}_{1}, \mathrm{~T}_{2}$ : Variável dependente, tensão de água no estádio vegetativo e tensão de água no estádio de bulbificação, respectivamente. * Valores obtidos para $\mathrm{T}_{1}$ e $\mathrm{T}_{2}$ iguais a $2,31 \mathrm{pF}(20 \mathrm{kPa})$.

to com tensão de $2,31 \mathrm{pF}(20 \mathrm{kPa})$, e 82 $\mathrm{mm}$, para o com tensão de $3,21 \mathrm{pF}$ (160 $\mathrm{kPa}$ ), em ambos os estádios.

A análise de variância indicou interação não significativa ( $p>0,05)$ entre os fatores tensão de água no solo no estádio vegetativo e tensão no estádio de bulbificação para todas as variáveis avaliadas. As funções de resposta ajustadas, para as variáveis que apresentaram correlação significativa com os fatores avaliados, são apresentadas na Tabela 1.

O desenvolvimento vegetativo das plantas, avaliado pela massa seca da parte aérea, apresentou correlação linear negativa com a tensão de água no solo no estádio vegetativo e quadrática com a tensão no estádio de bulbificação (Tabela 1). A massa seca da parte aérea, que atingiu um valor máximo de $1,462 \mathrm{t} \mathrm{ha}^{-1}$ para o tratamento com tensão de água no solo de 2,31 pF (20 kPa), em ambos os estádios de desenvolvimento, foi reduzida em até $70 \%$ à medida que as plantas foram submetidas a déficits crescentes de água no solo de até $3,21 \mathrm{pF}$ $(160 \mathrm{kPa})$. Menor desenvolvimento vegetativo, mesmo para plantas submetidas a condições moderadas de deficiência de água no solo, também foi reportado por Melo \& Oliveira (1999) e Marouelli et al. (2002).

A produtividade total, comercial e de bulbos graúdos e a massa média de bulbos apresentaram, similarmente, correlações lineares negativas com as tensões de água no solo, tanto no estádio vegetativo quanto no de bulbificação (Tabela 1). A maior produtividade de bulbos esteve associada à tensão máxi- ma de água no solo de 2,31 pF (20 kPa), em ambos os estádios de desenvolvimento das plantas.

Plantas submetidas a condições de deficiência hídrica mais severa (160 $\mathrm{kPa}$ ), tanto no estádio vegetativo quanto no de bulbificação, tiveram a produtividade total e comercial e a massa média de bulbos reduzidas em 50\%, $63 \%$ e $31 \%$, respectivamente, em relação à tensão de $20 \mathrm{kPa}$. A produtividade de bulbos graúdos foi desprezível quando se permitiu que as plantas utilizassem até $85 \%$ da água disponível no solo.

Os resultados de produtividade obtidos são compatíveis com aqueles relatados por Pola \& Biasi (1993) e Marouelli et al. (2002), os quais, para as condições edafoclimáticas de Santa Catarina e do Distrito Federal, respectivamente, obtiveram produtividade máxima de bulbos para tensões entre $13 \mathrm{e}$ $27 \mathrm{kPa}$. Diferem, no entanto, daqueles relatados por Vasconcellos et al. (1971) e Klar et al. (1972), que obtiveram produtividade máxima para a tensão de 50 $\mathrm{kPa}$. Pela função de resposta ajustada (Tabela 1), obtém-se que a redução na produtividade comercial de bulbos para uma tensão de $50 \mathrm{kPa}(2,71 \mathrm{pF})$ seria de $28 \%$. Tais diferenças, que podem ser atribuídas em parte às características das cultivares e edafoclimáticas predominantes nos diferentes estudos, podem ser devido, principalmente, aos sistemas de irrigação utilizados, que nos casos de Vasconcellos et al. (1971) e Klar et al. (1972) foi por sulco.

Como os resultados obtidos no presente estudo e os reportados por Pola \& Biasi (1993) e Marouelli et al. (2002) apresentaram resposta linear negativa da produtividade de bulbos à tensão de água no solo, pode-se inferir que valores de tensão abaixo de $20 \mathrm{kPa}$ podem proporcionar incrementos significativos de produtividade de bulbos de alho. Todavia, a manutenção de níveis muito elevados de água no solo pode prejudicar a qualidade e a conservação de bulbos (Vasconcellos et al., 1971; Higazy et al., 1974; Costa et al., 1993).

O número total de bulbos colhidos por unidade de área foi influenciado significativamente apenas pela tensão de água no solo no estádio vegetativo, decrescendo linearmente, em até $18 \%$, com o aumento da tensão (Tabela 1). Isso indica que a ocorrência de tensões máximas de água no solo, durante o estádio de bulbificação, de até $160 \mathrm{kPa}$, não provocou a morte de plantas ou $\mathrm{o}$ impedimento da formação de bulbos, mas prejudicou o desenvolvimento dos mesmos.

A eficiência do uso de água pela cultura, que variou de 0,86 a $1,99 \mathrm{~g} \mathrm{~L}^{-1}$, foi reduzida linearmente, em até $57 \%$, com o aumento das tensões de água no solo tanto no estádio vegetativo quanto no de bulbificação (Tabela 1), indicando estar diretamente correlacionada com a lâmina de água aplicada às plantas.

Com base nos resultados de produtividade e eficiência do uso de água, conclui-se que a cultura do alho é altamente sensível à deficiência de água no solo do plantio até o máximo desenvolvimento de bulbos. Assim, a ocorrência de deficiência de água durante o estádio vegetativo da cultura, mesmo que moderada, além de prejudicar o desen- 
volvimento das plantas, reduziu o número de bulbos por unidade de área, o tamanho de bulbos e, consequentemente, a produtividade de bulbos. Já a deficiência de água no solo no estádio de bulbificação provocou redução na produtividade por reduzir significativamente o tamanho dos bulbos.

Não houve ocorrência de bulbos pseudoperfilhados no intervalo de tensão de água no solo estudado. Semelhantemente, Klar et al. (1972) também não constataram a presença de pseudobulbos mesmo em plantas (cv. "Lavínia") submetidas a alta freqüência de irrigação (10 kPa). Vasconcellos et al. (1971), Costa et al. (1993) e Pola \& Biasi (1993), por outro lado, concluíram que essa anormalidade fisiológica é altamente correlacionada com o regime de irrigação, aumentando com níveis crescentes de água no solo. Segundo Menezes Sobrinho (1997), tal divergência é explicada pelo fato das cultivares "Amarante" e "Lavínia" apresentarem alta resistência ao pseudoperfilhamento.

As tensões de água no solo, aplicadas nos dois estádios das plantas, não afetaram significativamente $(\mathrm{p}>0,05)$ a percentagem de bulbos chochos (média de $0,13 \%$ ) e a percentagem de perda de massa de bulbos entre 60 e 120 dias (média de 9,3\%) e entre 120 e 180 dias (média de 7,7\%) após a colheita. Costa et al. (1993) e Marouelli et al. (2002) também não verificaram efeito signifi- cativo de diferentes níveis de água no solo sobre a incidência de bulbos chochos. Higazy et al. (1974), por outro lado, relatam que teores mais elevados de água no solo favoreceram maior perda de massa de bulbos durante o armazenamento. Entretanto, observa-se nos dados de Higazy et al. (1974) que a maior percentagem de perda de massa ocorrida para os tratamentos mais úmidos somente se deu durante os primeiros 30 dias após a colheita; daí até aos 150 dias a percentagem de perda de massa não foi significativamente afetada pelos níveis de água no solo a que as plantas foram submetidas.

Como o chochamento de bulbos não foi afetado pelas tensões de água no solo avaliadas, conclui-se que a menor produtividade de bulbos associadas às plantas submetidas a irrigações deficitárias deveu-se tanto pelo decréscimo do número de bulbos colhidos por unidade de área quanto pela redução do tamanho de bulbos.

\section{LITERATURA CITADA}

COSTA, T.M.P.; SOUZA, R.J.; SILVA, A.M. Efeitos de diferentes lâminas de água e doses de nitrogênio sobre a cultura do alho (Allium sativum L. cv. Juréia). Ciência e Prática, v. 17, n. 3, p. 239246, 1993.

HIGAZY, M.K.; SHANAN, S.A.; BILLAH, M.E.M.; RAMADAN, H.M. Effect of soil moisture levels on postharvest changes in garlic Egypt Journal of Horticulture, v. 1, n. 1, p. 13-22, 1974.
IBGE. Produção agrícola. Disponível: site SIDRA Sistema IBGE de recuperação automática. http: \wwww.sidra.ibge.gov.br/. Consultado em 14 dez. 2000.

KLAR, A.; SCALOPI, E.J.; VASCONCELOS, E.F.C. Potenciais de umidade do solo e nitrogênio em cobertura afetando uma cultura de alho (Allium sativum, L. var. "Lavínia"). Ciência e Cultura, v. 24, n. 11, p. 1045-1049, 1972.

MAROUELLI, W.A.; SILVA, W.L.C.; CARRIJO, O.A.; SILVA, H.R. Produção de alho sob diferentes tensões de água no solo e doses de nitrogênio. Horticultura Brasileira, Brasília, v. 20, n. 2, p.191194, 2002.

MAROUELLI, W.A.; SILVA, W.L.C.; SILVA, H.R. Manejo da irrigação em hortaliças. Brasília: EMBRAPA-SPI/EMBRAPA-CNPH, 1996. 72 p. MELO, J.P.L.; OLIVEIRA, A.P. Produção de alho em função de diferentes níveis de água e esterco bovino no solo. Horticultura Brasileira, v. 17, n. 1, p. 11-15, 1999.

MENEZES SOBRINHO, J.A. ed. Cultivo do alho (Allium sativum). 3. ed. Brasília: EMBRAPACNPH, 1997. 23 p. (Instruções Técnicas da Embrapa Hortaliças, 2).

POLA, A.C.; BIASI, J. Primeiros resultados experimentais de irrigação na cultura do alho em Caçador, SC. Agropecuária Catarinense, Florianópolis, v. 6, n. 2, p. 18-20, 1993.

REEVE, M.J; CARTER, A.D. Water release characteristic. In: SMITH, K.A.; MULLINS, C.E. Soil analysis: physical methods. New York: Marcel Dekker, 1991. p. 111-160.

SILVA, W.L.C.; CARRIJO, O.A.; OLIVEIRA, C.A.S.; MENEZES SOBRINHO, J.A. Irrigação da cultura do alho no Distrito Federal. Brasília: EMBRAPA-CNPH, 1981. 36 p. (Circular Técnica, 1).

VAN GENUCHTEN, M.T. A closed-form equation for predicting the hydraulic conductivity of unsaturated soils. Soil Science Society American Journal, v. 50, p. 288-291, 1980.

VASCONCELLOS, E.F.C.; SCALOPI, E.J.; KLAR, A. A influência da irrigação e adubação nitrogenada na precocidade e "superbrotamento" da cultura do alho (Allium sativum, L.). O Solo, v. 63 , n. 2 , p. $15-19,1971$. 